\title{
InToxicaÇÃo de Espécies de Eucalipto SubMetidas À DeRIVA do GLYPHOSATE $^{1}$
}

\author{
Intoxication of Eucalypt Species Under Glyphosate Drift
}

\author{
TUFFI SANTOS, L.D. ${ }^{2}$ FERREIRA, F.A. ${ }^{3}$, FERREIRA, L.R. ${ }^{3}$, DUARTE, W.M. ${ }^{4}$, TIBURCIO, R.A.S. ${ }^{5}$ \\ e SANTOS, M.V. ${ }^{6}$
}

\begin{abstract}
RESUMO - O glyphosate é o herbicida mais utilizado em áreas de reflorestamento de eucalipto. Nessas áreas tem sido freqüente a verificação de sintomas de intoxicação devido à deriva. Entretanto, trabalhos de pesquisa e observações de campo indicam comportamento diferencial entre as espécies e os clones de eucalipto quando em contato com o glyphosate. O presente trabalho teve como objetivo avaliar os efeitos da deriva simulada de glyphosate, por meio de doses reduzidas, no crescimento de cinco espécies de eucalipto. Utilizou-se o esquema fatorial 5x5, sendo cinco espécies (Eucalyptus urophylla, E. grandis, E. pellita, E. resinifera e E. saligna) e cinco doses ( $0 ; 43,2 ; 86,4 ; 172,8$; e 345,6 $\mathrm{g}$ ha $^{-1}$ de glyphosate), no delineamento em blocos casualizados com quatro repetições. A aplicação do herbicida foi feita sobre as plantas, de modo que não atingisse o terço superior, 23 dias após o plantio destas. Os sintomas de intoxicação causados pelo glyphosate foram semelhantes nas diferentes espécies, sendo caracterizados por murcha, clorose e enrolamento foliar, e, no caso de maiores doses, por necroses e senescência foliar. Plantas submetidas a doses acima de 86,4 $\mathrm{g} \mathrm{ha}^{-1}$ de glyphosate foram severamente intoxicadas, afetando o seu crescimento, resultando em menor altura, diâmetro do caule e massa seca aos 45 dias após aplicação do herbicida. Entre as espécies estudadas, E. resinifera foi mais tolerante à deriva de glyphosate, apresentando menores valores de intoxicação e maior incremento em altura e diâmetro, mesmo nas plantas submetidas às maiores doses, o que não foi observado nas demais espécies.
\end{abstract}

Palavras-chave: Eucalyptus spp., herbicida, tolerância.

\begin{abstract}
Glyphosate is the most used herbicide in eucalypt plantations. In these areas intoxication symptoms are often observed due to glyphosate drift. However, research works and field observations indicate different behaviors among eucalypt species and clones with glyphosate contact. This work aimed to evaluate the effects of simulated glyphosate drift, by means of herbicide subdoses, on the growth of five eucalypt species. The factorial model used five species (Eucalyptus urophylla, E. grandis, E. pellita, E. resinifera and E. saligna) and five subdoses $\left(0,43.2,86.4,172.8\right.$, and $345.6 \mathrm{~g} \mathrm{ha}^{-1}$ glyphosate) arranged in a randomized block design, with four repetitions. Glyphosate applications were performed on the plants in such a way as to avoid reaching the upper third part of the plants 23 days after seed planting. The intoxication symptoms caused by glyphosate were similar for the different species, as characterized by wilt, chlorosis and leaf curling and in the case of larger doses, by necrosis and leaf senescence. Plants treated with subdoses above $86.4 \mathrm{~g} \mathrm{ha}^{-1}$ glyphosate were severely intoxicated and were affected in their growth, with smaller height, diameter and less dry matter after 45 days of herbicide application. Among the species studied, E. resinifera showed to be the most tolerant to glyphosate drift, displaying the lowest intoxication values and greatest height and diameter increases, a fact not observed in the other species.
\end{abstract}

Keywords: Eucalyptus spp., herbicide, tolerance.

1 Recebido para publicação em 18.1.2006 e na forma revisada em 5.5.2006. Parte da dissertação de Doutorado do primeiro autor (Bolsista do CNPq).

2 Estudante de Doutorado em Fitotecnia - DFT/UFV, <ltuffi@yahoo.com.br>; ${ }^{3}$ Professor do Departamento de Fitotecnia, Universidade Federal de Viçosa - DFT/UFV, 36570-000 Viçosa-MG; ${ }^{4}$ Estudante de Agronomia; ${ }^{5}$ Estudante de Engenharia Florestal; ${ }^{6}$ Mestranda em Fitotecnia - DFT/UFV.

Planta Daninha, Viçosa-MG, v. 24, n. 2, p. 359-364, 2006 


\section{INTRODUÇÃO}

O gênero Eucalyptus compreende cerca de 800 espécies, sendo muitas delas utilizadas em cultivos comerciais destinados aos mais diversos usos, como: produção de papel, celulose e carvão vegetal, madeira para serraria, construção civil e indústria de móveis, postes e moirões, óleos essenciais, ornamentação, entre outros (Dourojeami, 2004).

Apesar de o gênero Eucalyptus apresentar espécies de rápido crescimento e de boa competitividade quanto a seu estabelecimento no campo, isso não o isenta dos prejuízos causados pelas plantas daninhas, que têm como conseqüência o decréscimo quantitativo e qualitativo da sua produção. A interferência das plantas daninhas é mais acentuada nos dois primeiros anos de produção; entretanto, em algumas áreas, o controle estende-se até o sexto ano, o que se justifica por questões de operacionalidade na colheita e por ganhos na produtividade. O custo de controle, a demanda de mão-de-obra, a importância na busca de maiores produções por área e os efeitos do herbicida no meio ambiente colocam as plantas daninhas na lista dos piores problemas da eucaliptocultura. De acordo com Toledo et al. (2003), o manejo das plantas daninhas em plantios de eucalipto é realizado basicamente por meio de métodos químicos e mecânicos, isolados ou combinados. No caso das extensas áreas cultivadas por empresas florestais, não só a escassez de mão-de-obra, como a necessidade de atingir elevados índices de produtividade têm levado ao aumento do uso do controle químico como alternativa para redução dos custos de produção (Ribeiro, 1988).

O glyphosate configura-se no herbicida mais usado na cultura do eucalipto, principalmente pelo efetivo controle de grande número de espécies daninhas e pelo baixo risco de contaminação ambiental (Malik et al., 1989). Herbicidas à base de glyphosate têm sido usados tanto no preparo da área quanto no plantio, replantio, no controle da rebrota das cepas e na manutenção de reflorestamentos de eucalipto. O maior problema do uso desse herbicida em eucalipto é a deriva acidental, a qual compromete o controle das plantas daninhas e leva ao aumento compensatório da dose utilizada, elevando os gastos e causando prejuízos às espécies não-alvo e ao meio ambiente (Hemphill Jr. \& Montgomery, 1981).

O efeito de formulações herbicidas, provenientes da deriva, em plantas não-alvo está diretamente ligado à quantidade do princípio ativo que chega às culturas, que por sua vez está associado às doses usadas no controle das plantas daninhas. Segundo Rodrigues \& Almeida (2005), as doses recomendadas do glyphosate para o eucalipto variam de 360 a $2.160 \mathrm{~g} \mathrm{ha}^{-1}$ para controle de espécies anuais e perenes. A utilização de doses elevadas de glyphosate em áreas infestadas por plantas daninhas perenes - geralmente com insucesso no controle - tem potencializado os riscos de danos com a deriva.

Em áreas em que o glyphosate vem sendo freqüentemente utilizado no controle de plantas daninhas em reflorestamento de eucalipto, são observados sintomas de intoxicação, em intensidades variáveis, devido à deriva. Trabalhos de pesquisa e observações de campo sugerem comportamento diferencial entre as espécies e nos clones de eucalipto perante o glyphosate.

O presente trabalho teve como objetivo avaliar os efeitos da deriva simulada de glyphosate, por meio de doses reduzidas, no crescimento de cinco espécies de eucalipto.

\section{MATERIAL E MÉTODOS}

O experimento foi realizado em casa de vegetação, pertencente ao Departamento de Fitotecnia da Universidade Federal de Viçosa, entre os meses de dezembro de 2004 e fevereiro de 2005.

Mudas padronizadas de Eucalyptus grandis, E. urophylla, E. saligna, E. pellita e E. resinifera, oriundas de semente, com três meses de idade e aproximadamente $30 \mathrm{~cm}$ de altura, foram plantadas em vasos preenchidos com $10 \mathrm{~L} \mathrm{de}$ solo argiloso, adubado com 216,6 g de N-P-K (6-30-6) e 12 g de calcário, cuja proporção $\mathrm{Ca} / \mathrm{Mg}$ era de 4:1 equivalentes. A adubação de cobertura foi realizada com $12 \mathrm{~g}$ por vaso de N-P-K (20-05-20), parcelado em três vezes, com intervalos entre as adubações de 20 dias. As plantas de eucalipto receberam irrigação por microaspersão, de modo a manter a 
disponibilidade de água próxima à capacidade de campo.

Utilizou-se o delineamento em blocos casualizados, com quatro repetições, sendo cada vaso, contendo uma planta, considerado uma parcela experimental. O ensaio foi instalado em esquema fatorial $5 \times 5$ (cinco espécies de eucalipto e cinco doses de glyphosate). As doses testadas foram: 43,2; 86,4; 172,8; e 345,6 $\mathrm{g} \mathrm{ha}^{-1}$ e.a. de glyphosate, correspondente respectivamente a 3, 6, 12 e $24 \%$ da dose de $1.440 \mathrm{~g} \mathrm{ha}^{-1}$ da formulação sal de isopropilamina, e uma testemunha sem herbicida (dose 0), para fins de comparação. O glyphosate, nas diferentes doses, foi aplicado 40 dias após o plantio das mudas, quando o eucalipto apresentava cerca de $45 \mathrm{~cm}$ de altura, de modo que não atingisse o terço superior das plantas. Para aplicação, utilizou-se pulverizador costal de precisão, munido de barra com dois bicos com pontas tipo leque TT110.02, espaçados de 0,5 m entre eles, operando a $250 \mathrm{kPa}$ de pressão e trabalhando com volume de calda correspondente a $200 \mathrm{~L} \mathrm{ha}^{-1}$. No momento da aplicação a umidade relativa do ar encontrava-se a $85 \%$, com temperatura de $26,5^{\circ} \mathrm{C}$ e velocidade do vento de aproximadamente $2 \mathrm{~km} \mathrm{~h}^{-1}$. As folhas das plantas permaneceram, 24 horas após a aplicação, protegidas do contato com água da chuva ou da irrigação, visando evitar a lavagem do produto.

Após a aplicação do herbicida foram observadas, diariamente, alterações morfológicas na parte aérea. Aos 15, 30 e 45 dias após a aplicação (DAA), determinou-se a porcentagem de intoxicação em relação à testemunha, em que $0 \%$ corresponde à ausência de sintomas visiveis e 100\% à morte das plantas (Frans, 1972).

Aos 45 DAA foram mensurados a altura das plantas (região entre o coleto e o ápice) e o diâmetro do caule a $1 \mathrm{~cm}$ do solo, sendo os valores subtraídos da altura e do diâmetro obtidos no dia da aplicação do glyphosate. Subtraindo a altura e o diâmetro aos 45 DAA pelos valores no dia da simulação da deriva, obteve-se a variação em altura e diâmetro por planta após a exposição à deriva do glyphosate. Aos 45 DAA, a parte aérea das plantas foi cortada rente ao solo e acondicionada em sacos de papel mantidos em estufa com circulação forçada de ar $\left(65 \pm 3{ }^{\circ} \mathrm{C}\right)$ até atingir peso constante, para obtenção da massa seca.

Os dados quantitativos foram submetidos à análise de variância e as médias comparadas a 5\% de probabilidade pelo teste de Tukey; utilizando-se o Aplicativo Computacional para Análises Genéticas e Estatísticas - GENES (Cruz, 1997).

\section{RESULTADOS E DISCUSSÃO}

A intoxicação das plantas variou de acordo com as doses testadas $(p<0,05)$ aos 15,30 e 45 dias após aplicação (DAA), sendo tanto maior quanto maiores as doses de glyphosate (Tabela 1). Houve variação entre as espécies $(\mathrm{p}<0,05)$ quanto à porcentagem de intoxicação, sendo a interação doses $\mathrm{x}$ espécie não-significativa $(\mathrm{p}>0,05)$.

Nas cinco espécies estudadas verificaramse murcha, clorose e enrolamento das folhas dos ápices das plantas pulverizadas com

Tabela 1 - Porcentagem de intoxicação de plantas de eucalipto submetidas à deriva do glyphosate, aos 15, 30 e 45 dias após aplicação (DAA). Viçosa-MG, 2006

\begin{tabular}{|l|c|c|c|c|c|}
\hline \multirow{2}{*}{ Clone } & \multicolumn{5}{|c|}{ Dose (g ha ${ }^{-1}$ de glyphosate) } \\
\cline { 2 - 6 } & 43,2 & 86,4 & 172,8 & 345,6 & Média \\
\hline & \multicolumn{5}{|c|}{$\%$ de intoxicação aos 15 DAA } \\
\hline E. grandis & 2,75 & 21,25 & 38,75 & 65,00 & $25,45 \mathrm{~A}$ \\
\hline E. pellita & 3,50 & 20,00 & 52,50 & 65,00 & $28,20 \mathrm{~A}$ \\
\hline E. resinifera & 1,25 & 8,75 & 31,25 & 32,50 & $14,75 \mathrm{~B}$ \\
\hline E. saligna & 0,75 & 17,50 & 50,00 & 62,50 & $26,15 \mathrm{~A}$ \\
\hline E. urophylla & 0,75 & 22,50 & 65,00 & 65,00 & $30,65 \mathrm{~A}$ \\
\hline Média & $1,80 \mathrm{C}$ & $18,00 \mathrm{~B}$ & $47,50 \mathrm{~A}$ & $58,00 \mathrm{~A}$ & \\
\hline & \multicolumn{5}{|c|}{$\%$ de intoxicação aos $30 \mathrm{DAA}$} \\
\hline E. grandis & 4,00 & 32,50 & 50,00 & 63,75 & $30,05 \mathrm{~A}$ \\
\hline E. pellita & 2,00 & 27,50 & 55,00 & 77,50 & $32,40 \mathrm{~A}$ \\
\hline E. resinifera & 2,00 & 15,00 & 22,50 & 32,50 & $14,40 \mathrm{~B}$ \\
\hline E. saligna & 0,00 & 20,00 & 50,00 & 61,25 & $26,25 \mathrm{~A}$ \\
\hline E. urophylla & 0,00 & 31,25 & 62,00 & 77,50 & $34,15 \mathrm{~A}$ \\
\hline Média & $1,60 \mathrm{C}$ & $25,25 \mathrm{~B}$ & $47,90 \mathrm{~A}$ & $62,50 \mathrm{~A}$ & \\
\hline & \multicolumn{5}{|c|}{$\%$ de intoxicação aos 45 DAA } \\
\hline E. grandis & 12,50 & 33,75 & 50,00 & 83,75 & $36,00 \mathrm{~A}$ \\
\hline E. pellita & 3,25 & 32,50 & 60,00 & 85,00 & $36,15 \mathrm{~A}$ \\
\hline E. resinifera & 5,00 & 14,50 & 30,00 & 45,00 & $18,90 \mathrm{~B}$ \\
\hline E. saligna & 5,00 & 25,00 & 56,25 & 70,00 & $31,25 \mathrm{~A}$ \\
\hline E. urophylla & 2,00 & 33,50 & 60,00 & 77,50 & $34,60 \mathrm{~A}$ \\
\hline Média & $5,55 \mathrm{C}$ & $27,85 \mathrm{~B}$ & $51,25 \mathrm{~A}$ & $72,25 \mathrm{~A}$ & \\
\hline
\end{tabular}

Médias seguidas da mesma letra não diferem significativamente entre si pelo teste de Tukey a $5 \%$ de probabilidade. 
as doses de 172,8 e $345,6 \mathrm{~g}^{\mathrm{ha}^{-1}} \mathrm{e}$, em menor intensidade, com 86,4 $\mathrm{g} \mathrm{ha}^{-1}$ de glyphosate. Os sintomas tornaram-se visiveis a partir do quarto DAA em E grandis, E. pellita e E. urophylla e do quinto DAA em E. resinifera e E. saligna. Aos $15 \mathrm{DAA}$, as plantas de eucalipto que receberam as doses de 172,8 e 345,6 $\mathrm{g} \mathrm{ha}^{-1}$ de glyphosate apresentavam folhas coriáceas, ápices deformados, necroses bem desenvolvidas nos bordos das folhas e senescência foliar acentuada. Sintomas foliares semelhantes em plantas de eucalipto submetidas à deriva simulada com glyphosate foram relatados por Tuffi Santos et al. (2005, 2006). A clorose pode ser resultado da degeneração dos cloroplastos (Campbell et al., 1976) e/ou da inibição da formação de clorofila (Cole et al., 1983) em plantas tratadas com glyphosate.

As doses de 172,8 e $345,6 \mathrm{~g} \mathrm{ha}^{-1} \mathrm{de}$ glyphosate provocaram a morte dos ápices das plantas, verificada aos 15 DAA, em Eucalyptus grandis, E. urophylla, E. saligna e E. pellita; nessas espécies, a intoxicação das plantas alcançou valores superiores a 62 e $70 \%$ aos 15 e 45 DAA, respectivamente (Tabela 1). Em E. resinifera não foi observada a morte dos ápices, sendo nesta espécie observada menor intoxicação em todas as épocas de avaliação, aproximadamente $50 \%$ dos valores das demais espécies (Tabela 1), mostrando-se, portanto, mais tolerante à deriva do glyphosate. O comportamento diferencial entre os genótipos submetidos à deriva de glyphosate foi relatado por Tuffi Santos et al. (2006), em que o clone de E. grandis foi mais suscetivel ao herbicida que clones de E. urophylla e eucalipto urograndis.

Plantas de E. urophylla submetidas à aplicação de 172,8 e 345,6 $\mathrm{g}_{\text {ha-1 }}{ }^{-1}$ de glyphosate emitiram novas brotações, porém com baixa intensidade de intoxicação, mesmo quando expostas à maior dose. Já em E. pellita e E. grandis o surgimento de novas brotações só ocorreu em plantas pulverizadas com 172,8 g e.a. ha-1 de glyphosate, sendo elas caracterizadas por brotações retorcidas, com folhas reduzidas e cloróticas. Dantas et al. (2001), trabalhando com glyphosate no controle da rebrota de cepas em diferentes clones de eucalipto, relatam o surgimento de brotações com sintomas de intoxicação. Tuffi Santos et al. (2005) também descreveram a emissão de brotações normais, e com sintomas de intoxicação, em mudas de eucalipto submetidas às doses de 172,8 e 345,6 g e.a. ha ${ }^{-1}$ de glyphosate, respectivamente.

A massa seca, a altura e o diâmetro das plantas diferiram $(\mathrm{p}<0,01)$ entre doses de glyphosate utilizadas, bem como para a variável altura entre espécies. Não foi verificada variação entre espécies $(p>0,05)$ para massa seca, diâmetro de plantas e para interação doses $x$ espécies $(p>0,05)$ nas variáveis analisadas.

Todas as espécies submetidas a 172,8 e $345,6 \mathrm{~g} \mathrm{ha}^{-1}$ de glyphosate apresentaram menor massa seca e altura aos 45 DAA; com $345,6 \mathrm{~g} \mathrm{ha}^{-1}$ de glyphosate o diâmetro das plantas também foi o menor observado entre as doses testadas. A dose de 43,2 $\mathrm{g} \mathrm{ha}^{-1}$ mostrou resultados semelhantes aos da testemunha (Tabela 2). As injúrias severas que levaram à paralisação do crescimento e à senescência das folhas justificam a redução de altura, diâmetro e matéria seca observada nas plantas expostas às maiores doses.

Tabela 2 - Matéria seca, altura e diâmetro do caule de cinco espécies de eucalipto submetidas à deriva do glyphosate, aos 45 dias após aplicação. Viçosa-MG, 2006

\begin{tabular}{|c|c|c|c|c|c|c|}
\hline \multirow{2}{*}{ Clone } & \multicolumn{6}{|c|}{ Doses ( $\mathrm{g} \mathrm{ha}^{-1}$ de glyphosate) } \\
\hline & 0 & 43,2 & 86,4 & 172,8 & 345,6 & Média \\
\hline & \multicolumn{6}{|c|}{ Massa Seca $(\mathrm{g})$} \\
\hline E. grandis & 103,31 & 90,11 & 64,27 & 39,05 & 26,82 & $64,71 \mathrm{~A}$ \\
\hline E. pellita & 108,02 & 89,56 & 57,39 & 28,48 & 17,81 & $60,25 \mathrm{~A}$ \\
\hline E. resinifera & 91,85 & 81,36 & 67,25 & 37,93 & 39,88 & $63,65 \mathrm{~A}$ \\
\hline E. saligna & 94,5 & 94,81 & 40,82 & 23,59 & 24,83 & $55,71 \mathrm{~A}$ \\
\hline E. urophylla & 95,98 & 86,38 & 51,51 & 20,68 & 21,41 & $55,19 \mathrm{~A}$ \\
\hline \multirow[t]{2}{*}{ Média } & $98,73 \mathrm{~A}$ & $88,44 \mathrm{~A}$ & $56,24 \mathrm{AB}$ & $29,95 \mathrm{~B}$ & $26,15 \mathrm{~B}$ & \\
\hline & \multicolumn{6}{|c|}{ Altura $(\mathrm{cm})$} \\
\hline E. grandis & 100,00 & 88,50 & 65,75 & 49,00 & 49,50 & $70,55 \mathrm{~B}$ \\
\hline E. pellita & 106,25 & 95,25 & 73,25 & 53,75 & 52,75 & $76,25 \mathrm{AB}$ \\
\hline E. resinifera & 119,75 & 108,50 & 107,25 & 64,75 & 66,25 & $93,30 \mathrm{~A}$ \\
\hline E. saligna & 87,75 & 81,75 & 63,75 & 48,00 & 47,25 & $65,70 \mathrm{~B}$ \\
\hline E. urophylla & 119,25 & 121,00 & 72,75 & 58,75 & 60,25 & $86,40 \mathrm{AB}$ \\
\hline \multirow[t]{2}{*}{ Média } & $106,60 \mathrm{~A}$ & $99,00 \mathrm{~A}$ & $76,55 \mathrm{AB}$ & $54,85 \mathrm{~B}$ & $55,20 \mathrm{~B}$ & \\
\hline & \multicolumn{6}{|c|}{ Diâmetro $(\mathrm{cm})$} \\
\hline E. grandis & 1,25 & 1,18 & 1,13 & 1,04 & 0,87 & $1,09 \mathrm{~A}$ \\
\hline E. pellita & 1,36 & 1,31 & 1,15 & 1,07 & 0,76 & $1,13 \mathrm{~A}$ \\
\hline E. resinifera & 1,19 & 1,14 & 1,15 & 1,06 & 1,09 & $1,13 \mathrm{~A}$ \\
\hline E. saligna & 1,22 & 1,21 & 1,04 & 0,90 & 0,89 & $1,05 \mathrm{~A}$ \\
\hline E. urophylla & 1,23 & 1,27 & 1,14 & 0,94 & 0,87 & $1,09 \mathrm{~A}$ \\
\hline Média & $1,25 \mathrm{~A}$ & $1,22 \mathrm{~A}$ & $1,12 \mathrm{AB}$ & $1,00 \mathrm{AB}$ & $0,89 \mathrm{~B}$ & \\
\hline
\end{tabular}

Médias seguidas da mesma letra não diferem significativamente entre si pelo teste de Tukey a $5 \%$ de probabilidade. 
Entre as espécies estudadas, E. resinifera, E. urophylla e E. pellita obtiveram as maiores alturas aos 45 DAA (Tabela 2). Por sua vez, E. grandis apresentou a menor altura entre as espécies (Tabela 2), provavelmente devido aos severos sintomas de intoxicação em plantas expostas às doses de 172,8 e $345,6 \mathrm{~g} \mathrm{ha}^{-1}$ de glyphosate (Tabela 1), principalmente pela morte dos ápices e pela não-emissão de brotações que retomassem o crescimento das plantas, como observado nas demais espécies.

Nas Figuras 1 e 2 é mostrada a variação em altura e diâmetro de plantas, respectivamente, durante um período de 45 dias após exposição à deriva simulada de glyphosate. E. pellita, E. grandis, E. urophylla e E. saligna apresentaram perda em altura após exposição à deriva simulada com as doses de 172,8 e 345,6 $\mathrm{g} \mathrm{ha}^{-1}$ de glyphosate (Figura 1), resultante da morte e senescência dos ápices causada pelo herbicida. A dose de 86,4 $\mathrm{g} \mathrm{ha}^{-1}$ de glyphosate reduziu a altura das plantas de todas as espécies, exceto em E. resinifera, que nesta dose apresentou comportamento semelhante ao de plantas não expostas ao herbicida, com ganhos em altura de praticamente o dobro daqueles de indivíduos das demais espécies (Figura 1). E. resinifera foi a espécie que apresentou os maiores ganhos em diâmetro quando submetida à deriva do glyphosate, contrastando com E. urophylla, que teve o pior comportamento quando pulverizada com as doses de 172,8 e $345,6 \mathrm{~g} \mathrm{ha}^{-1}$ de glyphosate (Figura 2).

Os resultados evidenciam os prejuízos da deriva de glyphosate no crescimento de eucalipto, alertando para os cuidados a serem tomados com a tecnologia de aplicação de herbicidas na eucaliptocultura. Maior tolerância à deriva do glyphosate foi constatada em E. resinifera, quando comparada às demais espécies estudadas. A suscetibilidade variável entre os genótipos é o ponto de partida para a busca do entendimento dos mecanismos envolvidos na tolerância de plantas ao glyphosate, além de evidenciar a importância de reduzir a deriva durante a aplicação deste herbicida em reflorestamentos de eucalipto. $\mathrm{Na}$ literatura, trabalhos demonstram que a tolerância ao glyphosate é devida à penetração ou translocação diferencial (Sandberg et al., 1980;

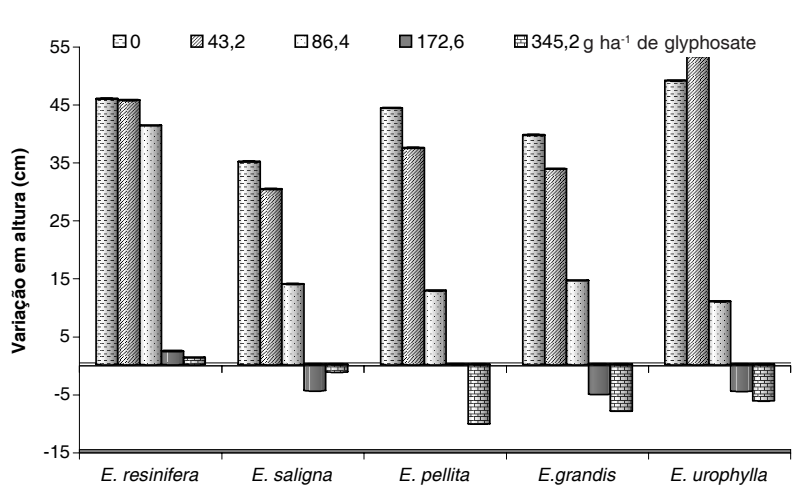

Figura 1 - Ganho em altura de plantas de eucalipto, no período de 45 dias, após simulação de deriva de glyphosate. Viçosa-MG, 2006.

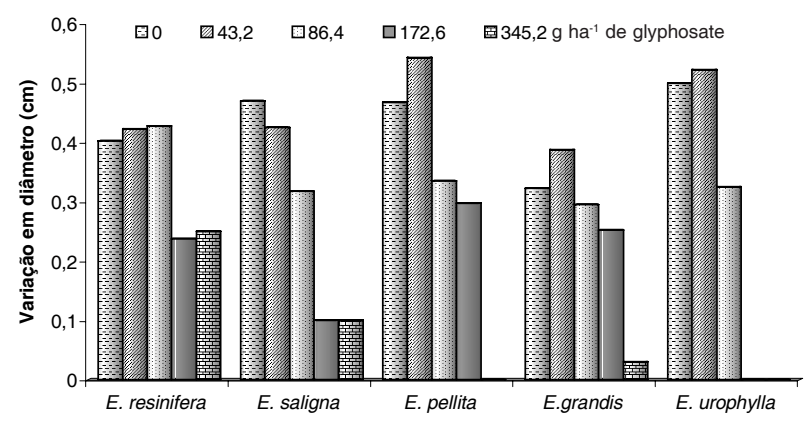

Figura 2 - Ganho em diâmetro do caule de plantas de eucalipto, no período de 45 dias, após simulação de deriva de glyphosate. Viçosa-MG, 2006.

D’Anieri et al., 1990; Satichivi et al., 2000; Monquero et al., 2004). As taxas de absorção foliar de herbicidas e, conseqüentemente, sua eficácia estão diretamente ligadas aos tipos de estruturas encontradas na folha e à permeabilidade das cutículas (Baker, 1982), que, por sua vez, dependem da constituição e da polaridade dos componentes da cutícula. Assim, faz-se necessário estudos sobre anatomia e micromorfologia foliar de Eucalyptus spp., bem como sobre a constituição de ceras e cutícula, que possam fornecer subsídios que expliquem a tolerância diferencial entre E. resinifera, E. pellita, E. grandis, E. urophylla e E. saligna.

\section{LITERATURA CITADA}

BAKER, E. A. Chemistry and morphology of plant epicuticular waxes. In: CUTLER, D. F.; ALVIN, K. L.; PRICE, C. E. (Eds.). The plant cuticle. London: Academic Press, 1982. p. 140-161. 
CAMPBELL, W. F.; EVANS, J. O.; REED, F. C. Effect of glyphosate on chloroplast ultrastructure of quack grass mesophyll cell. Weed Sci., v. 24, p. 22-25, 1976.

COLE, D. J.; CASELEY, J. C.; DODGE, A. D. Influence of glyphosate on selected plant process. Weed Res., v. 23, p. 173-183, 1983.

CRUZ, C. D. Programa GENES: aplicativo computacional em genética e estatística versão Windows. Viçosa, MG: Universidade Federal de Viçosa, 2001.

D'ANIERI, P. et al. Glyphosate translocation and efficacy relationships in red maple, sweet gum and loblolly pine seedlings. For. Sci., v. 36, p. 438-447, 1990.

DANTAS, F. W. F.; SOUZA, A. J.; CIERO, A. D. Controle da rebrota de eucalipto em área de reflorestamento. In: SEMINÁRIO NACIONAL SOBRE HERBICIDAS E TECNOLOGIA DE APLICAÇÃO EM FLORESTAS, 2001, Viçosa-MG. Anais... Viçosa, MG: SBS/SIF, 2001. p. 29-44.

DOUROJEAMI M. O eucalipto não é vilão. Sociedade Brasileira de Silvicultura. 2004. Disponível em: <http:// www.sif.com.br>. Acesso em: 18 set. 2005.

FRANS, R. E. Measuring plant responses. In: WILKINSON, R. E. (Ed.). Research Methods in Weed Science. [S.1.]: Southern Weed Science Society, 1972. p. 28-41.

HEMPHILL JR., D. D.; MONTGOMERY, M. L. Response of vegetable crops to sub lethal application of 2,4-D. Weed Sci., v. 29, n. 6, p. 632-635, 1981.

MALIK, J.; BARRY, G.; KISHORE, G. The herbicide glyphosate. Biofactores, v. 2, p. 17-25, 1989.
MONQUERO, P. A. et al. Caracterização da superfície foliar e das ceras epicuticulares em Commelina benghalensis, Ipomoea grandifolia e Amaranthus hybridus. Planta Daninha v. 22, p. 203-210, 2004.

RIBEIRO, G. T. Uso de herbicidas pré-emergentes em Eucalyptus sp. na região do cerrado. In: SEMINÁRIO TÉCNICO SOBRE PLANTAS DANINHAS E O USO DE HERBICIDAS EM REFLORESTAMENTO, 1988, Rio de Janeiro. Anais... Rio de Janeiro: SBS/ABRACAVE/SIF, 1988.

RODRIGUES, B. N.; ALMEIDA, F. S. Guia de herbicidas. Londrina: 2005. 591 p.

SANDBERG, C. L.; MEGGITT, W. F.; PENNER, D. Absorption, translocation and metabolism of ${ }^{14} \mathrm{C}$-glyphosate in several weed species. Weed Res., v. 20, p. 195-200, 1980 .

SATICHIVI, N. M. et al. Absorption and translocation of glyphosate isopropylamine and trimethysulfonium salts in Abutilon theophrasti and Setaria faberi. Weed Sci., v. 48, p. 675-679, 2000.

TOLEDO, R. E. B. et al. Faixas de controle de plantas daninhas e seus reflexos no crescimento de plantas de eucalipto. Sci. For., v. 64, p. 78-92, 2003.

TUFFI SANTOS, L. D. et al. Crescimento e morfoanatomia foliar de eucalipto sob efeito de deriva do glyphosate. Planta Daninha, v. 23, n. 1, p. 133-142. 2005.

TUFFI SANTOS, L. D. et al. Morphological responses of different eucalypt clones submitted to glyphosate drift (in press). Environ. Exp. Bot., 2006. No prelo. 